\title{
The value of decision support models for farmer learning
}

R.W. WEBBY

AgResearch Ruakura, PB 3123, Hamilton

rex.webby@agresearch.co.nz

\begin{abstract}
Advances in computer technologies and mathematical modelling have enabled technology providers to develop decision support tools. Studies with farmer groups showed that the value of these tools to farmers may be as much for learning as for decision support. Stockpol was used in one farmer group to support decisions around farm systems design. Quickfeed was developed with another group that were interested in pasture quality, and Bestbreed with a group whose target was lamb growth rate from birth to weaning. The ultimate aim in all three studies was to improve farm profitability. When evaluating the studies, farmers ranked the overall study as being highly effective (72 to $86 \%$ ) in achieving the goal of improved profitability yet the value of the models was ranked much lower (40 to $44 \%$ ). This result may be explained by the perception value relates to hands on use, rather than the learning associated with using the model and interaction with the information encapsulated in the model. Here the learning environment included collecting information to use in the model and comparing the model output with the actual changes that had occurred on farms. In other words, farmers were learning through participation. The value to farmers of computer models or tools may be better measured by their success in improving farm profitability. In these studies, this lay directly in what the farmers learnt and how their behaviour changed as a result of participation in the overall study rather than in continued use of the models per se. This paper discusses this aspect of farmer learning and the benefits of packaging technology in the form of decision support tools.
\end{abstract}

Keywords: computer technologies, decision support, farmer study groups, learning, mathematical modelling, technology providers

\section{Introduction}

Mixed sheep, beef cattle and deer farms in New Zealand are based on a diversity of enterprises. A single farm produces a variety of products e.g., wool, mutton, lamb, manufacturing beef, prime beef, venison and velvet, and store livestock. Such enterprises are highly complex with a multitude of interactions amongst interacting farm system components. This complexity makes it difficult for farmers to value the way new information will benefit their farm business, leaving a wealth of technology unused. This apparent apathy has been a quandary to technology providers who may well have failed to realise the importance of fit of new technology into a farm system in determining its level of adoption. Understanding this fit and the inherent limitations imposed is the key to presenting and packaging new technologies and practices. Computer modelling allows us to develop tools that can help scientists understand the interactions in a farm system and test new technologies and ideas.

Over the past decade, farmer groups have evolved through group farm monitoring (Webby \& Sheath 1991-1993; Rhodes \& Aspin 1993) to study groups (Sheath et al. 1999) that focus on gaining knowledge on a particular aspect or technology. Part of the process of these study groups has involved the use of or the development of computer models. This paper describes the learning associated with the development and/or use of computer-based farm decision support models for three group projects run in the upper North Island (Webby \& Paine 1997; Sheath et al. 1999; Webby \& Johnstone 2001).

\section{Materials}

Three groups of sheep and beef cattle farmers were involved in this study. One of the groups, located in the King Country Region and described by Webby \& Paine (1997), Sheath et al. (1999) and Hanna (2001), was involved in two projects. The first which ran from 1995 to 1998 involved the computer programme Stockpol (Marshall et al. 1991) and the second, which ran from 1998 to 2000, involved the development and use of the computer based lamb production model Bestbreed (Woodward et al. 2001). The other group which was in

Table 1 Groups and computer programmes involved with learning tools.

\begin{tabular}{cllll}
\hline Study & Group & Years & Location & Computer model \\
\hline 1 & NKC & 1995 to 1998 & King Country & Stockpol \\
2 & NKC & 1998 to 2001 & King Country & Bestbreed \\
3 & West Waikato & 1998 to 2000 & Waikato & Quickfeed \\
\hline
\end{tabular}


the Waikato (Webby \& Johnstone 2001), ran from 1998 to 2000 and involved the computer model 'Quickfeed' (Woodward et al. 2000).

\section{Methods}

In each of the studies the intent was to develop and/or use a decision support tool as a farm management aid, and ultimately to improve farm profitability.

\section{Study 1: Improving product consistency by reducing feeding variability}

The aim here was for farmers to use Stockpol as a management tool to reduce product variability thus enabling supply to specifications such as number, carcass weight and timeliness. Being able to predict feed supply well before a deficit occurred and to know the feed requirements of all classes of stock on the farm meant targets were more likely to be achieved.

The study involved 27 farmers monitoring and collecting information such as live weights and pasture covers. All farmers in the Group were involved with loading and running their own information in Stockpol during seven structured workshops over a 3 year period.

\section{Study 2: The interaction of breeding and feeding on lamb weaning weight}

A group of 14 farmers from Study 1 undertook a further study to look at improving lamb and ewe performance from lamb birth to lamb weaning in an environment of increasing lambing percentage (from 120 to $150 \%$ ) with the target of improving weaning weight at the same age. The model Bestbreed, was proposed at the start of the study and engineered during the course of the study. As the model was developed farmers used their own data to test the model and predict outcomes.

\section{Study 3: The interaction of feed quantity and quality}

A group of 12 farmers undertook a study to help farm through adverse summer-autumn conditions in the Waikato. The 'Quickfeed' model was developed to help decision making in terms of feed quality and quantity and its allocation to livestock. The tool enabled farmers to predict live weight gains using pasture cover and the metabolic energy concentration of the pasture (ME).

At the end of each study the participating farmers answered a questionnaire. Its purpose was to evaluate the success of the study, and the farmers were asked to rank the value (as a percentage) of their involvement in the study, in terms of (1) increasing farm profitability and (2) using the model as a decision support tool in achieving the outcome in (1).

\section{Results and discussion}

The questionnaire responses suggested a high degree of success in meeting the first criterion of increasing farm profitability, rankings ranging from $72-86 \%$ (Table 2).

Table 2 Study value (\%) as ranked by the farmers involved.

\begin{tabular}{ccc}
\hline Study & To farm profitability & Usefulness of Model \\
\hline 1 & 81 & 40 \\
2 & 72 & 40 \\
3 & 86 & 44 \\
\hline
\end{tabular}

However, rankings were much lower for the second criterion (usefulness of the model in achieving increased profitability), ranging from $40-44 \%$. There were a number of key components to these studies which should be taken into account when interpreting these results. Firstly the farmers had a learning objective at the start; secondly they monitored what was going on and were able to measure change. Thirdly the model was relevant to the learning needs of farmers.

From these results, the models appear to have been of more apparent value to farmers as learning tools rather than as decision-support tools. This perceived benefit of decision support models is often overlooked. A model may be criticised because of the apparent lack of use when in fact it has been highly useful in delivering information and learning. Farm profitability improved yet usage of and competency in the model's use was not necessarily high.

When participating in the training workshops and seeing on screen the interactions that occur within a farm system, a typical farmer comment was "now I understand". Despite hearing and reading what scientists and consultants have said over many years about a particular subject the message was not understood until shown in the context of the relationships and interactions that occur within the farm system. It's probable that many scientists and farm consultants have struggled to demonstrate the contextual relevance of technologies because they have struggled to understand or demonstrate the interactions that may occur as a result of changing farm practice.

Stockpol (Marshall et al. 1991), although never intended as a way of packaging technology, is a good example of software designed purely as a decision support tool. It can be used to analyse a farm system and packages an immense amount of scientific information. Its value however to farmers and scientists may be quite different. The farmer gains from the experience of using the model, the encapsulation of their farm system in the model and the exposure to the science that is packed into it. Being able to understand how one key component such as lambing date affects the rest of the farm as a system can be a significant learning experience for a farmer. In this way Stockpol is a powerful learning tool and whether or 
not they continue to use it may be less important than the learning experience gained from the initial involvement with the programme.

Pasture cover is sometimes raised particularly in the context of feed budgeting and ME in the context of feeding value. All these parameters are relevant when feeding livestock on pasture. Pasture cover affects the bite size and biting rate and therefore the ability to achieve a desired intake rate (quantity) and ME, particularly of lower quality feeds, also affects intake rate (Nicol et al. 1987). These and other factors such as paddock area, numbers and class of livestock and time interact to give a result. Not easy to explain or understand until seen as the one screen interactive model 'Quickfeed'. One look at an interaction on the screen may well be enough for a farmer to gain a new understanding of feeding livestock. This interaction between the farmer and the model may be enough to change the farmers' decision making to the extent of not needing to refer to the model again.

This concept of using computer models as learning tools has been taken further. Lambert \& Litherland (2000) summarised practical principles of pasture quality, and Lambert et al. (2000) reported on how sheep \& beef farmers manage pasture quality. This information has been captured by Woodward et al. (2001) in a computer model called Q-Graze which is being used in a nationwide Meat NZ funded project sharing the pasture quality message with farmers.

The models used in this study are tools to support farm decision making and as such do not necessarily have to be used regularly. Their complexity means that to retain competency as a user, regular use is important. For a farmer, it may not be practical to maintain a high level of user competency and a better solution for them may well be to employ a competent user when required. Stockpol again is a good example of this; its use may only be required when a change in stock policy is contemplated.

Technology providers should value computer models as a way of packaging new information. The benefits to farmers come from the learning associated with interacting with the model and gathering the information for use in the model, and in comparing the models outputs with what actually occurs. This is in contrast to the expectation that value will only come from being a competent user of the model.

\section{REFERENCES}

Hanna, A.B.; Hanna, A.M.; Webby, R.W. 2001. Farm monitoring to future contracts: The Hanna's experience. Proceedings of the New Zealand Grassland Association 63: 29-32.

Lambert, M.G.; Litherland, A.J. 2000. A practitioners guide to pasture quality. Proceedings of the New
Zealand Grassland Association 62: 111-115.

Lambert, M.G.; Paine, M.S.; Sheath, G.W.; Webby, R.W.; Litherland, A.J.; Fraser, T.J.; Stevens, D.R. 2000. How do sheep and beef farmers manage pasture quality? Proceedings of the New Zealand Grassland Association 62: 117-121.

Marshall, P.R.; McCall, D.G.; Johns, K.L. 1991. Stockpol: A decision support model for livestock farms. Proceedings of the New Zealand Grassland Association 53: 137-140.

Nicol, A.M. 1987. Ed: Livestock feeding on pasture. New Zealand Society of Animal Production Occasional Publication No.10.

Rhodes, A.P.; Aspin, M.D. 1993. MRDC Monitor farms - using information. Proceedings of the New Zealand Grassland Association 55: 23-26.

Sheath, G.W.; Webby, R.W.; Keeling, P.; Thomson, R.D.; Page, C.R.; Burton, .G.T. 1999. The results and success factors of nine group farm monitoring programmes. Proceedings of the New Zealand Society of Animal Production 59: 87-90.

Webby, R.W.; Sheath, G.W. 1991. Group monitoring, a basis for decision making and technology transfer on sheep and beef farms. Proceedings of the New Zealand Grassland Association 53: 13-16.

Webby, R.W.; Sheath, G. W. 1993. Farm Monitoring, away to improve performance on sheep and beef farms. Proceedings of the International Grassland Congress XVII: 791-792.

Webby, R.W.; Paine, M.S. 1997. Farmer groups: a measure of their effectiveness. Proceedings of the New Zealand Society of Animal Production 57: 109111.

Webby, R.W.; Johnstone, L.J.C. 2001. Reducing the impact of adverse summer-autumn pasture conditions on livestock performance: results from farmer experience. Proceedings of the New Zealand Grassland Association 63: 229-233.

Woodward, S.J.R.; Johnstone, L.J.C.; Webby, R.W. 2000. A decision tool for calculating herbage mass and metabolisable energy requirements of growing cattle and sheep. Proceedings of the New Zealand Grassland Association 62: 13-18.

Woodward, S.J.R.; Lambert, M.G.; Litherland, A.J.; Boom, C.J. 2001. Can a mathematical model accurately predict intake of grazing animals? Testing the Q-Graze model. Proceedings of the New Zealand Society of Animal Production 61: 4-7.

Woodward, S.J.R.; Webby, R.W.; Binnie, D.B. 2001. A farmer decision tool for simulating and optimising lamb production. Proceedings of the International Congress on Modelling and Simulation (MODSIM 2001), 10-13 December 2001, Australian National University, Canberra, Australia. Vol. 4, 1695-1700. 